\title{
El inadmisible encanto de la violencia. Policías y barras en una comparación antropológica
}

José Garriga Zucal

Buenos Aires: Cazador de Tormentas

2015, 144 páginas

\section{GUILLERMINA LAITANO*}

Universidad Nacional de Mar del Plata / Conicet

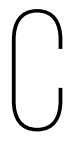

onceptualmente relevante, el libro de José Garriga Zucal trata sobre la violencia, un tema siempre escurridizo, inasible dirá el autor. Su propuesta es abordarlo desde una investigación etnográfica y comparativa cuyo objetivo es comprender las lógicas que rigen las acciones violentas. De esta forma, no pretende denunciar la violencia allí donde la registra, ni su predisposición subjetiva es la de la indignación moral; por el contrario, procura alejarse de estas posiciones y aproximarse al objeto de estudio desde renovados lentes analíticos. En este sentido, su apuesta consiste en repensar el concepto de violencia desde las propias prácticas violentas para observar la racionalidad que expresan. Su tesis es que "la violencia es un recurso que los actores usan situacionalmente" (9).

En las primeras páginas del libro el autor presenta la propuesta teórica a partir de la cual observará y comprenderá a su inaprensible objeto. Partiendo de las ideas de que violencia es un concepto que se define relacionalmente, de que cada definición situacional de violencia expresa el resultado de una disputa por los significados de las prácticas y de que en nuestra sociedad definir al otro como violento implica impugnar sus prácticas, Garriga Zucal define la violencia como recurso,

Socióloga, becaria doctoral del Consejo Nacional de Investigaciones Científicas y Técnicas, doctoranda en Historia por la Universidad Nacional del Centro de la Provincia de Buenos Aires. guillermina.laitano@yahoo.com. 
[...] entendiendo que las acciones que algunos definen como violentas pueden ser consideradas herramientas válidas en un contexto determinado de relaciones sociales, para alcanzar ciertos fines. En concreto, acceder a bienes materiales u obtener valores simbólicos relevantes puede ser objeto de estas acciones que unos repudian y otros aprueban. (10)

A continuación menciona las dos formas que asume el uso de la violencia en tanto recurso: como modo de pertenencia y como práctica que se adjudica a un otro para invisibilizar la propia, y señala que ambos usos son inadmisibles. Garriga Zucal expone cuatro advertencias conceptuales que desarrollará a lo largo del libro. Primero, es necesario resituar a la violencia dentro del campo social - y no desplazarla como si se tratara de un fenómeno "anormal"-; es decir, las acciones violentas también son formas de sociabilidad. Segundo, las acciones definidas como violentas no son, en ningún caso, carentes de sentido; de lo que se trata precisamente es de localizar y comprender las lógicas socialmente construidas en torno a ellas. Tercero, la violencia no debe ser naturalizada, no hay sujetos violentos sino prácticas violentas. Y, por último, si bien la violencia se define socialmente como ilegítima en términos morales, es necesario rastrear las diversas legitimidades que se construyen alrededor de esta.

Las referencias empíricas provienen de dos de sus investigaciones etnográficas, una sobre integrantes de la barra de Huracán - equipo de fútbol argentino-y otra sobre miembros de la policía de la provincia de Buenos Aires. Las técnicas empleadas en ambas investigaciones fueron la observación participante, la entrevista y la historia de vida. Sucintamente, el autor reconstruye el acceso al campo, elabora una descripción de ambas instituciones y los entramados sociales que allí se despliegan. En cuanto a los actores sobre los que focaliza el trabajo, en el caso de la barra de Huracán se trata de toda su estructura jerárquica: los capos, las piernas y la banda. En el caso de la policía, se enfoca en los uniformados que patrullan o hacen la calle en el conurbano bonaerense, es decir, los que trabajan en seguridad y prevención (en oposición a quienes realizan tareas administrativas o de investigación). Sorteando un sesgo común entre los cientistas sociales, el autor repara en la heterogeneidad de procedencias y trayectorias sociales que presentan los sujetos de los casos analizados. La incorporación del análisis de los orígenes sociales de los sujetos es clave si no se quiere confundir prácticas violentas con sujetos violentos.

En el texto, el lector encontrará un conjunto de reflexiones sobre el método etnográfico y la técnica de la observación participante. El autor menciona —más que la necesidad - la obligación de la reflexividad antropológica, esto es, el reconocimiento que el propio etnógrafo hace de sí mismo en tanto sujeto moral y 
político, así como sobre las dificultades de llevarla a cabo. La reflexividad del etnógrafo en esta investigación es la que le permite abordar el tema de la violencia desde una mirada renovada, al reconocer sus propios prejuicios morales de clase y suspenderlos cuanto sea posible para comprender las lógicas que operan y explican las acciones violentas de otros.

En el capítulo 1 el autor da cuenta del modo en que se utiliza la violencia en los dos universos estudiados. Al localizar los sentidos construidos por los actores, observa cómo ciertas prácticas que el resto de la sociedad define como violentas son utilizadas por barras y policías como recursos para obtener respeto. Este es el caso del aguante, que para los barras consiste en "poner el cuerpo" en enfrentamientos físicos con otras barras o frente a la represión policial, y del correctivo para los policías, el cual incluye un conjunto de acciones violentas de distinto gradiente que se utilizan cuando el civil se muestra irrespetuoso (por ejemplo, puñetazos en la cabeza, cachetadas y palizas). El aguante es la fuente de donde emana el respeto entre compañeros o frente a otras barras; es un recurso a partir del cual se construye la pertenencia al grupo. El correctivo es utilizado como herramienta que permite a los policías restituir un tipo de relación social que ha sido puesta en duda por el irrespeto del civil. El aguante y el correctivo son prácticas mediante las cuales barras y policías respectivamente obtienen honor y prestigio dentro del grupo.

Por otro lado, el autor analiza cómo opera la dimensión de género en las prácticas violentas de barras y policías. En el caso de las barras esta dimensión emerge fuertemente, pues quien posee aguante es identificado por el grupo con lo masculino - asociado a un papel activo y una posición dominante-, mientras que quien no posee aguante, o lo padece, es identificado con lo no-masculino —asociado a la pasividad y la subordinación-. En el caso de los policías, la investigación no registra diferencias sustantivas en la aplicación del correctivo que se expliquen por la dimensión de género.

En la sección final del capítulo, el autor describe la lógica racional que opera en estas acciones desde el punto de vista de los sujetos que las practican. En este sentido, la violencia del aguante emerge no como una acción caótica y desordenada, sino como una acción racional y legítima en el marco de un determinado sistema moral que detenta el grupo. De igual forma, el correctivo no se aplica de la misma manera a cualquier sujeto ni a cualquier tipo de irrespeto; en su empleo inciden variables como la posición de clase, de género y de edad del civil y del policía, así como el contexto sociopolítico. A partir de esta restitución de sentidos y racionalidades, el autor argumenta la pertinencia de no imponer 
subjetividades violentas donde lo que hay son acciones — definidas por otroscomo violentas.

Ahora bien, la violencia es un recurso que tanto barras como policías utilizan en la medida en que lo consideran legítimo. En el capítulo 2 Garriga Zucal ahonda en los criterios de legitimidad que barras y policías construyen sobre sus prácticas. Las características que hacen del aguante una acción violenta para el resto de la sociedad —que la barra no desconoce— son para sus integrantes símbolos de prestigio, distinción y pertenencia grupal. La barra disputa los sentidos atribuidos al aguante y lo valora positivamente. Por su parte, la policía entiende que su accionar violento es legítimo en tanto constituye una réplica a una acción previa. Es decir, las agresiones policiales son vistas y justificadas como reacciones necesarias - y extralimitaciones tolerables - ante la violencia de un otro civil o delincuente.

El autor analiza cómo las interacciones sociales que establecen tanto barras como policías por fuera de sus respectivos entramados sociales cumplen un papel en la producción de legitimidad de la violencia como recurso. En el caso de los barras esta legitimidad está dada por las relaciones sociales que entablan con otros actores sociales, tales como dirigentes deportivos y políticos, jugadores, policías, organizaciones delictivas, entre otros. Estas relaciones, aunque conflictivas, son estables y se caracterizan por la mutua dependencia entre los actores (basada en el intercambio de bienes materiales y simbólicos). En el caso de los policías, la legitimidad de la violencia como recurso se sustenta en la construcción de una alteridad civil o delincuente, que al actuar de modo violento justifica el correctivo policial.

Para concluir el estudio, en el capítulo 3 Garriga Zucal reflexiona sobre algunas particularidades de la violencia como recurso, con el objeto de contribuir al desarrollo de esta noción como concepto teórico. En primer lugar analiza los criterios de visibilidad: la violencia debe mostrarse ante los otros, debe exhibirse, pues solo así puede ser reconocida y suscitar respeto. Pero los márgenes de exhibición son diferentes entre barras y policías, "hay que exhibir el recurso, pero hay que saber cómo, cuándo y dónde” (112). Mientras que los primeros procuran mostrarlo más allá del límite grupal, los segundos - por cuestiones obvias-necesitan mantener su visibilidad acotada al mundo de los pares.

En segundo lugar, Garriga Zucal sitúa las violencias de barras y policías en el contexto social donde se desarrollan, mostrando que no son prácticas aisladas. Así como la barra hace uso del aguante frente a otras barras o frente a la represión policial, en otros contextos sociales, como el barrio, la política o el trabajo, también puede dirimir sus problemas mediante la lucha física: en este sentido, 
"la pelea exhibe una legitimidad que excede el mundo del fútbol" (116). De manera similar, en sus relatos los policías dan cuenta de otras situaciones en las que las prácticas violentas también son legítimas, por ejemplo enfrentamientos a puños con presos (sin esposar) para que ambos, policías y presos, "se saquen las ganas".

En tercer lugar, el antropólogo señala la compleja relación existente entre las matrices culturales que dan sustento a las legitimidades del aguante y el correctivo y las condiciones sociales estructurales (concretamente analiza la pertenencia de clase de los sujetos), relación que hace posible una interpretación multicausal de las violencias y que permite superar prejuicios enquistados en el sentido común dominante (como aquel que dicta que la violencia es una práctica específica de los sectores populares). Al hacer énfasis en que aquello que condiciona no determina, el autor sostiene que la violencia es un recurso que tienen los actores entre una multiplicidad de repertorios de acción disponibles.

Para concluir, Garriga Zucal hace explícita su práctica de reflexividad antropológica al reconocerse como un sujeto moral y político, y propone un modo de intervención para prevenir la violencia. En función de su análisis señala que, "para prevenir sus diferentes formas, [se debe] destruir los valores que habilitan la emergencia de legitimidades violentas” (133), puesto que mientras las prácticas violentas sean valoradas como prácticas legítimas para acceder a la membresía grupal y obtener respeto o prestigio, los sujetos continuarán haciendo uso de ellas en tanto un repertorio más de acción disponible.

Finalmente, presentamos dos comentarios sobre el libro que esperamos puedan ser aportes útiles para investigaciones futuras en torno a este complejo y escurridizo objeto de estudio. El primero de ellos se refiere conjuntamente a la cuestión de la interpretación del antropólogo y de la práctica reflexiva. Garriga Zucal propone utilizar la categoría violencia como concepto teórico para analizar los términos nativos aguante y correctivo. Sin embargo, la categoría violencia no solo es una construcción teórica del autor, sino también un término nativo, no de los grupos a los que el autor estudia, sino de un heterogéneo conjunto de otros que, en principio y esquemáticamente, podemos definir como el resto de la sociedad. A su vez, hay una tercera utilización del término violencia, la del propio autor en tanto sujeto moral y político. En este sentido, la incorporación de la distinción y problematización de estos tres usos de la noción de violencia, como concepto teórico y como término nativo - tanto del conjunto social como del investigador-, podría constituirse en un nuevo aporte para profundizar el estudio de la violencia.

El segundo comentario es de índole teórica. Al analizar la práctica violenta en tanto recurso movilizable por un actor, consideramos que se corre el riesgo de concebir tanto al actor como a la violencia de manera demasiado racional. De una parte, como si el actor tuviera conocimiento de sus prácticas y ejerciera 
un total dominio sobre ellas. De otra, se limita lo violento a la acción consciente, pasando por alto otras relaciones violentas que no se pueden atribuir a la acción consciente de un sujeto particular. Otro riesgo es que la violencia quede reducida a algo que se posee, algo así como un valor de cambio a partir del cual se obtiene prestigio y respeto, y se descuide el análisis de la violencia como lazo social que estructura subjetividades y relaciones.

Por ello creemos que sería fructífero abrir el análisis en sentido histórico y estructural. En el primer caso, si bien el autor menciona que las prácticas violentas son elaboraciones históricas, sería interesante profundizar en una reconstrucción que dé cuenta de cómo emergieron y cristalizaron las prácticas del aguante y del correctivo en cada grupo.

En el segundo caso, además de pensar las prácticas del aguante y del correctivo como recursos utilizables por cada grupo situacionalmente, sería relevante incorporar el análisis del conjunto de relaciones sociales más amplias donde ambos grupos están insertos y que podría aportar otras claves interpretativas sobre sus prácticas. En este punto, si bien el autor menciona que pertenecer al grupo, para el caso de la barra, incluye a los sujetos en una red de relaciones sociales más amplia conformada por dirigentes deportivos y políticos, jugadores, policías, organizaciones delictivas, entre otros — red que implica el intercambio de bienes materiales y simbólicos-, lo cierto es que para el autor lo que define en última instancia a la práctica del aguante es el interés de los barras en ser reconocidos por sus pares como parte del grupo. En el caso de los policías sería interesante pensar cómo se relacionan las prácticas como el correctivo con un conjunto más amplio de actores que incluya a las altas jerarquías de la fuerza policial y a los actores políticos que ejercen su gobierno.

Ampliar la mirada analítica en sentido histórico y estructural permitiría pensar cómo se relacionan prácticas como el aguante y el correctivo que se destacan por su visibilidad - al tratarse de formas de violencia física-, con otras formas de violencia, invisibilizadas pero determinantes en el modo en que se ordena lo social. Dicho en otras palabras, permitiría pensar cuál es la relación entre las formas de violencia analizadas por el autor y las formas sociales de dominación y explotación.

Por último, más allá de estos comentarios realizados con el espíritu de fomentar el debate, consideramos que El inadmisible encanto de la violencia es un libro sumamente relevante en la medida en que fomenta y amplía la reflexión sobre un concepto fundamental para pensar múltiples problemáticas que atañen a toda nuestra región. Si de lo que se trata es de conocer la realidad social para transformarla, el estudio de aquellos temas que por complejos y dolorosos nos incomodan se torna fundamental. 